\title{
Rancang Bangun Prototype Robot Pendeteksi Gas Metana Berbasis Mikrokontroler Arduino Untuk Eksplorasi Pertambangan
}

\author{
Ahnaf Faisal, Lovely Son \\ Jurusan Teknik Mesin, Fakultas Teknik, Universitas Andalas, Padang, Indonesia
}

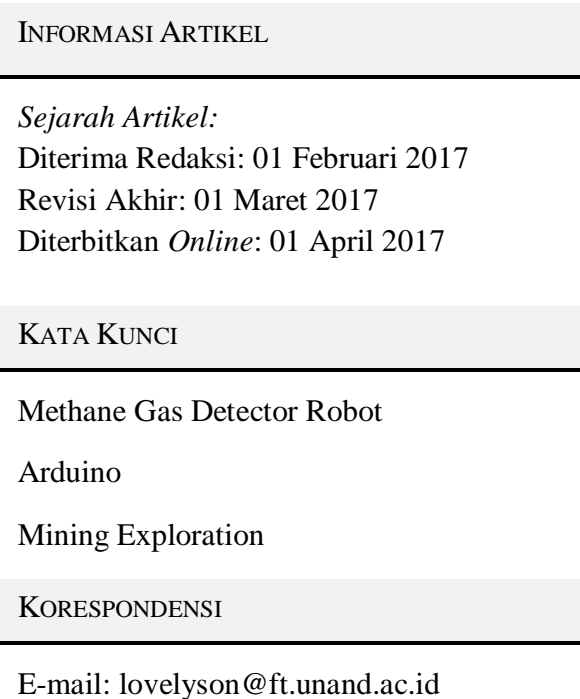

\section{PENDAHULUAN}

Keamanan kerja merupakan kebutuhan mutlak yang diperlukan manusia saat bekerja. Bekerja didaerah pertambangan merupakan pekerjaan yang potensial meraih keuntungan besar, karena nilai jual hasil tambang yang tinggi. Meskipun, keuntungan yang diperoleh besar, tetapi resiko yang harus dihadapi pun besar. Salah satu contohnya adalah bocornya gas berbahaya pada lokasi penambangan. Kebocoran gas dapat menimbulkan ledakan pada daerah tambang, seperti kasus tewasnya 33 penambang akibat meledaknya gas metana tambang di Sawahlunto, Sumatera Barat, Selasa (16/6/2010) [1].

Terdapat beragam jenis kondisi daerah pertambangan, ada yang minim gas berbahaya, namun ada juga yang sangat rentan terhadap resiko gas berbahaya. Beberapa gas berbahaya dapat dikenali melalui baunya yang khas, seperti gas sulfur (S), klor $(\mathrm{Cl})$ dan lain-lain. Akan tetapi kondisi ini tidak berlaku untuk gas seperti metana $\left(\mathrm{CH}_{4}\right)$, yang tidak berbau [2]. Pada kasus ini manusia tidak dapat mengenali perbedaan gas tersebut dengan udara biasa. Karena itulah sering terjadinya kecelakan di daerah tambang diakibatkan 
oleh gas metana. Dengan terjadinya beberapa kasus kecelakaan kerja, maka akan berdampak pada kenyamanan penambang dalam bekerja, serta biaya penyantunan yang harus dikeluarkan oleh perusahaan.

Salah satu upaya yang dapat dilakukan untuk mengatasi permasalahan tersebut adalah penggunaan robot yang berfungsi sebagai pendeteksi gas $\mathrm{CH}_{4}$. Robot pendeteksi gas berbahaya ini bersifat tidak diam di satu tempat, tetapi dapat bergerak ke tempat yang diinginkan oleh penambang dan dapat dipantau dari jarak jauh. Pendeteksian gas metana menggunakan robot sangat cocok digunakan pada daerah tambang karena mampu menjangkau daerah yang sulit dan tidak membutuhkan daya listrik yang besar dalam pengoperasiannya. Dalam hal ini, daya yang diberikan berasal dari baterai yang dapat diisi ulang. Pada penelitian ini dilakukan perancangan dan pembuatan prototype robot pendeteksi gas metana untuk membantu mengatasi permasalahan yang dialami perusahaan pertambangan guna memastikan keamanan kerja.

\section{TINJAUAN PUSTAKA}

\subsection{Sistem Robot Pendeteksi Gas Metana}

Pada dasarnya sistem robot pendeteksi gas metana ini menggunakan prinsip sistem kendali. Sistem kendali ini terdiri dari sensor, kontroler, dan aktuator. Sensor adalah komponen yang digunakan untuk mengukur suatu besaran dan akan meneruskan perubahan besaran dalam bentuk sinyal ke kontroler. Kontroler adalah suatu alat yang digunakan untuk memutuskan tindakan yang dilakukan aktuator bila mendapat sinyal dari sensor. Aktuator adalah komponen yang digunakan untuk menghasilkan suatu perubahan fisik berdasarkan sinyal yang diberikan oleh kontroler. Skema sistem kendali dapat dilihat pada Gambar 1. Komponen sistem kendali pada pendeteksi gas metana secara umum yakni sensor berupa sensor gas, kontrolernya menggunakan mikrokontroler, dan aktuatornya adalah speaker.

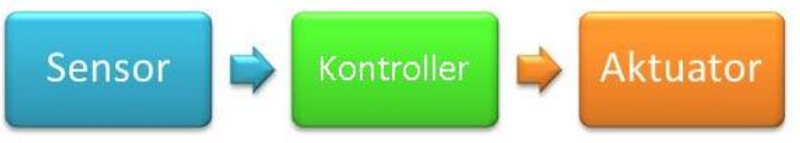

Gambar 1. Skema sistem kendali robot

\subsection{Bagian-Bagian Robot}

Secara garis besar, sistem kendali robot terdiri atas 2 bagian utama, yakni bagian mekanik dan elektronik. Selain kedua bagian tersebut, terdapat juga perangkat lunak yang berfungsi sebagai penghubung antara operator dengan sistem kendali. Disamping itu, perangkat lunak juga ditujukan agar robot memiliki kecerdasan tertentu [3]. Bagian mekanik merupakan bagian-bagian konstruksi dan penggerak robot yang terdiri atas motor DC, gearbox, dan rangka robot. Bagian elektronika merupakan rangkaian pengendali dan catu daya yang terdiri atas komponen-komponen elektronika seperti: sensor, aktuator, baterai, dan mikrokontroler [4].

\subsection{Rangkaian Penyuplai Daya Listrik}

Sebagai komponen pensuplai daya (charger), baterai memiliki batasan waktu penggunaan. Bila habis, maka diperlukan rangkaian untuk dapat mengisi kembali baterai yang telah habis. Karena baterai merupakan sumber daya DC, maka diperlukanlah pengisi daya yang dapat merubah suplai daya AC dari PLN menjadi DC. Sebuah charger dapat dibuat dengan empat buah komponen utama, yaitu transformator, penyearah, kapasitor, serta regulator.

\section{METODOLOGI}

Tahapan yang dilakukan dalam penelitian ini ditunjukkan dalam bentuk diagram alir seperti terlihat pada Gambar 2. Berikut diterangkan tentang tahap-tahap dalam penelitian yang telah dilakukan: 


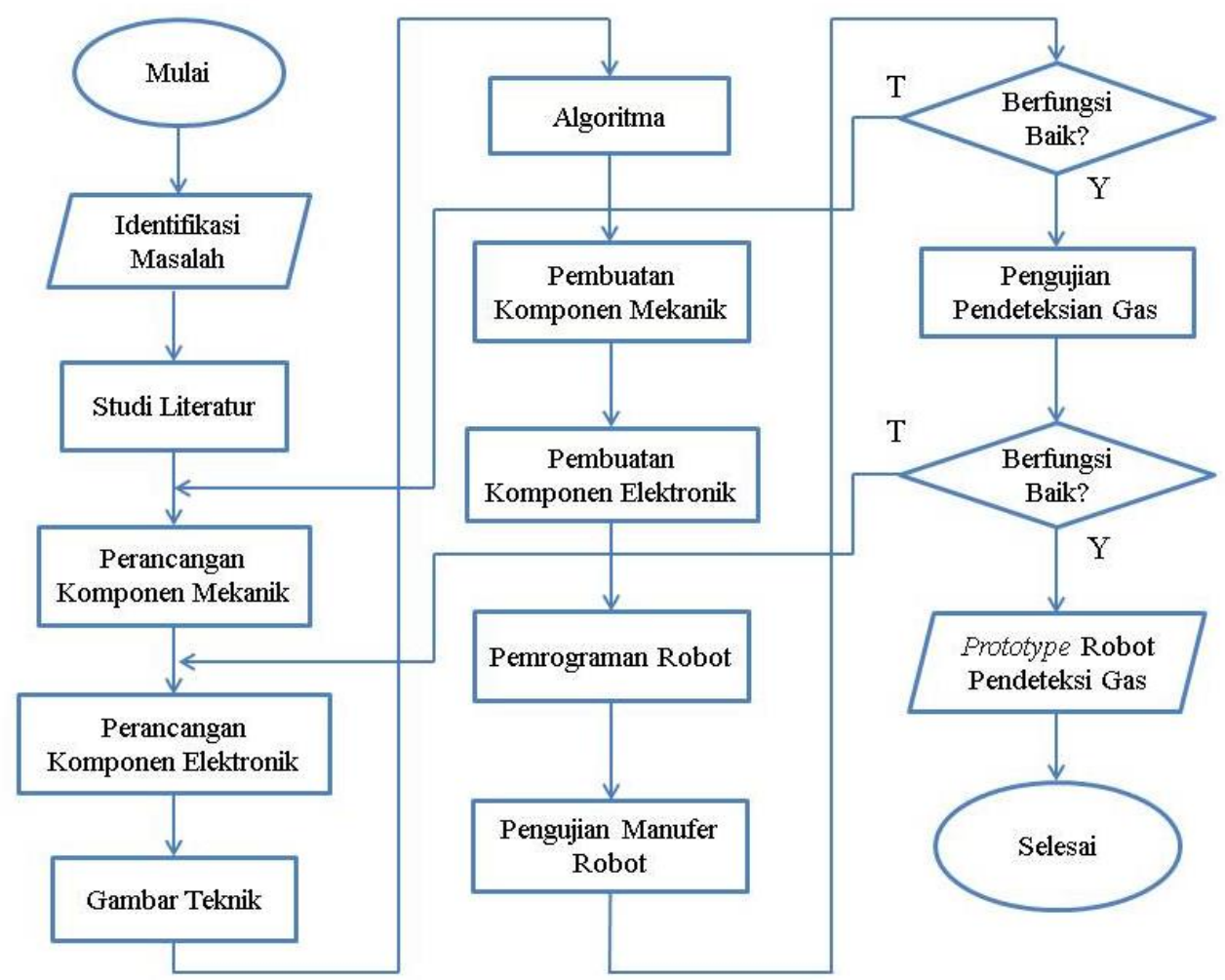

Gambar 2. Diagram Alir Pelaksanaan Tugas Akhir

\subsection{Perancangan Komponen Robot Pendeteksi Gas Metana}

Tahap perancangan robot berfungsi untuk mempermudah proses pembuatan alat. Perancangan dilakukan berdasarkan studi literatur yang telah dilakukan. Robot yang digunakan diharapkan dapat mendeteksi gas metana dan dapat melintasi medan off road. Robot ini akan menuju ke tempat yang dicurigai terdapat gas metana, dengan kontrol robot menggunakan hp android.

Robot diprogram dengan 3 level kadar gas metana, yakni rendah, sedang, dan tinggi. Bila kadar gas metana yang terdeteksi rendah, maka tempo alarm buzzer dan nyala led akan lambat. Semakin tinggi kadar gas metana, maka temponya akan semakin cepat.

\subsubsection{Perancangan Komponen Mekanik}

Sistem mekanik yang dirancang untuk robot pendeteksi gas metana memiliki bentuk seperti robot mobil dengan 4 roda. Komponen mekanik utama pada robot, yakni rangka robot, roda gigi, poros, dan roda. Sistem mekanik ini akan digerakkan oleh motor dc.

Robot memiliki berat $1,09 \mathrm{~kg}$. Koefisien gesek antara ban karet dengan jalan beton $\left(\mu_{\mathrm{s}}=0,85\right)$ [37]. Sehingga, gaya yang dibutuhkan untuk menggerakan robot adalah lebih besar dari gaya gesek robot $\left(\mathrm{Fs}=\mu_{\mathrm{s}} \mathrm{N}\right)$, yakni lebih besar dari 0,9265 N. Dengan persamaan $(T=F . r)$, jari-jari roda $(\mathrm{r}) 3,7 \mathrm{~cm}$, dan gaya $(\mathrm{F}) 0,9265 \mathrm{~N}$, maka torsi (T) yang diperlukan untuk menggerakan robot adalah lebih besar dari 3,428 N.cm.

\subsubsection{Perancangan Komponen Elektronik}

Sistem elektronik yang dirancang pada robot adalah sistem kendali utama berupa mikrokontroler arduino. Mikrokontroler arduino ini selanjutnya disambungkan dengan power bank, rangkaian sensor gas, rangkaian receiver remote control, rangkaian Driver motor yang disambungkan dengan baterai, dan rangkaian speaker dan lampu robot. 
Detail jenis-jenis rangkaian dari sistem ini adalah:

a. Rangkaian Catu Daya

Rangkaian catu daya adalah rangkaian yang mensuplai daya dari baterai dan juga power bank. Baterai difokuskan untuk menghidupkan motor, sedangkan Power Bank difokuskan untuk menghidupkan mikrokontroler arduino, receiver bluetooth, sensor gas metana, buzzer, dan led. Skema rangkaian catu daya dapat dilihat pada Gambar 3 .

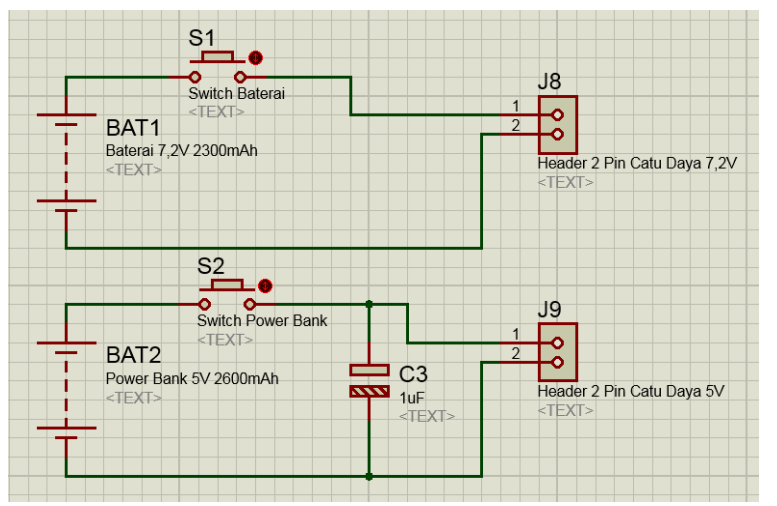

Gambar 3. Skema rangkaian catu daya

b. Rangkaian Sensor MQ-04

Rangkaian Sensor MQ-04 berfungsi untuk mendeteksi keberadaan gas metana, dan mengirimkan sinyal hasil pengukuran ke mikrokontroler. Pada rangkaian ini digunakan Trimpot 10k yang bertujuan agar sensor dapat dikalibrasi dengan cara mengatur besarnya hambatan pada trimpot. Skema rangkaian Sensor MQ-04 dapat dilihat pada Gambar 4.

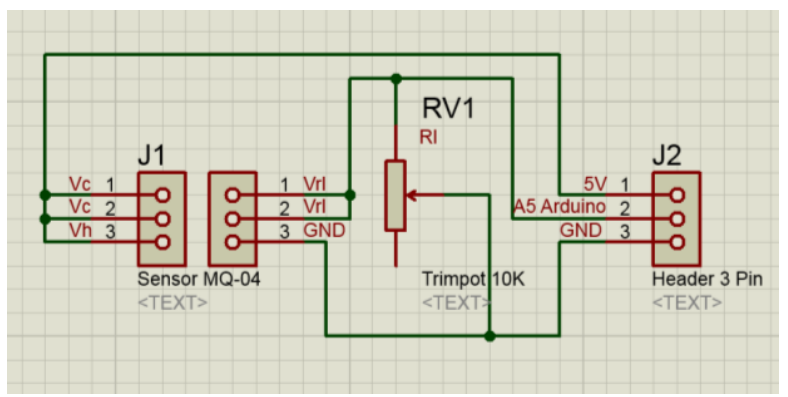

Gambar 4. Skema rangkaian Sensor MQ-04

c. Rangkaian Bluetooth HC-05

Rangkaian Bluetooth HC-05 adalah rangkaian yang digunakan untuk menerima sinyal dari HP Android yang telah terkoneksi dengan robot. Setelah sinyal dari HP Android diterima, selanjutnya dikirimkan sinyal ke Mikrokontroler Arduino pada port TX dan RX. Selain menerima sinyal dari HP Android, melalui rangkaian ini sinyal dari mikrokontroler juga dapat dikirimkan dan diterima oleh HP Android. Skema rangkaian Bluetooth HC-05 dapat dilihat pada Gambar 5.

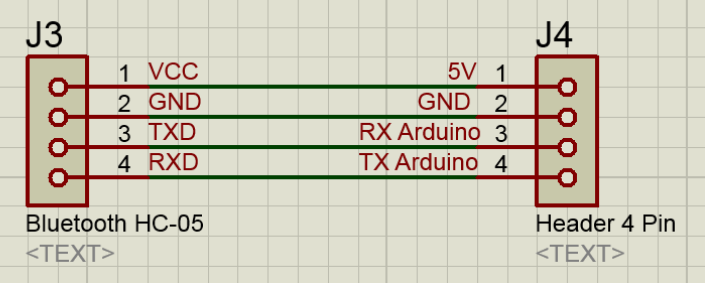

Gambar 5. Skema rangkaian Bluetooth HC-05

d. Rangkaian Arduino

Rangkaian arduino merupakan pusat dari seluruh sistem robot. Untuk menghidupkan rangkaian ini dibutuhkan catu daya $5 \mathrm{~V}$. Pada bagian input dari arduino dihubungkan dengan sensor (A5), TX-RX Bluetooth HC-05 (RXTX Arduino). Pada bagian output dihubungkan dengan Driver motor (D2, D4, D7, D8), dan Buzzer-LED indikator (D12). Skema dari rangkaian Arduino dapat dilihat pada Gambar 6.

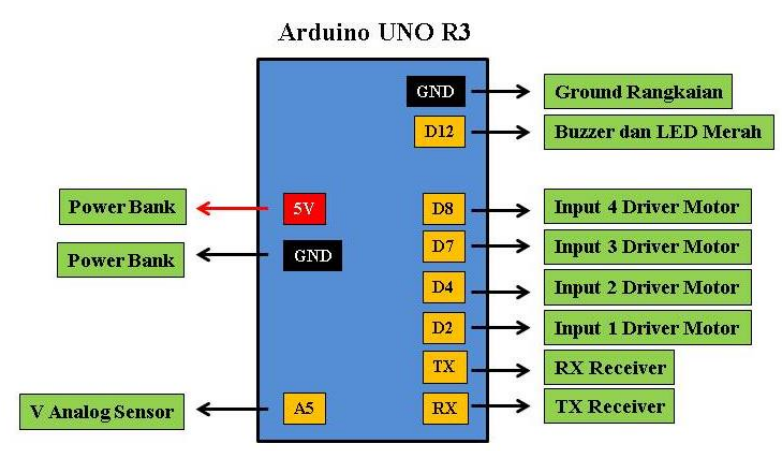

Gambar 6. Skema rangkaian Arduino

e. Rangkaian Driver Motor

Rangkaian Driver Motor merupakan rangkaian yang digunakan untuk menghidupkan dan mematikan motor penggerak robot. Rangkaian ini berpusat pada IC H-Bridge L298, yang memungkinkan pengontrolan gerakan 2 motor dc secara CW dan CCW. Pada kaki 4 IC diberikan inputan tegangan $7,2 \mathrm{~V}$ yang 


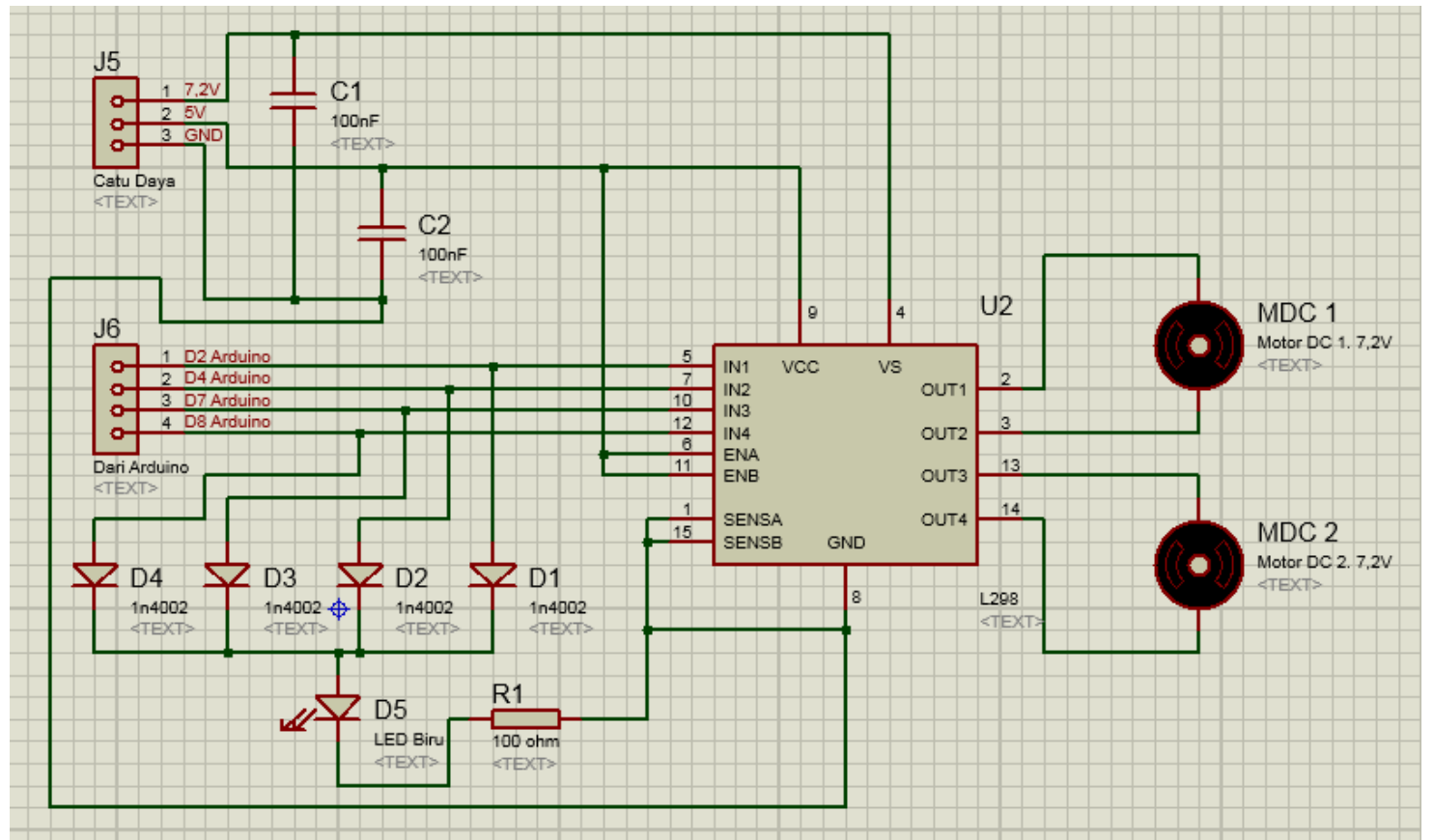

Gambar 7. Skema rangkaian Driver Motor

berfungsi untuk menjalankan motor, sedangkan pada kaki 9 diberikan input tegangan $5 \mathrm{~V}$ yang berfungsi sebagai sinyal reverensi untuk masukan sinyal pada kaki 5,7,10,12 dari Arduino. Inputan 5V ini juga berguna untuk menghidupkan motor yakni pada kaki 6 dan 11 IC. Skema rangkaian Driver motor dapat dilihat pada Gambar 7.

\subsection{Pembuatan Gambar Teknik}

Setelah proses perancangan komponen mekanik dan elektronik dilakukan, maka hasil perancagan tersebut akan dituangkan dalam bentuk gambar teknik. Hasil rancangan mesin pendingin akan digambar dengan menggunakan perangkat lunak Computer Aided Design (CAD). Gambar teknik tersebut berfungsi untuk memudahkan proses pembuatan robot pendeteksi gas metana nantinya. Gambar 3D hasil rancangan robot pendeteksi gas metana diperlihatkan pada Gambar 8.

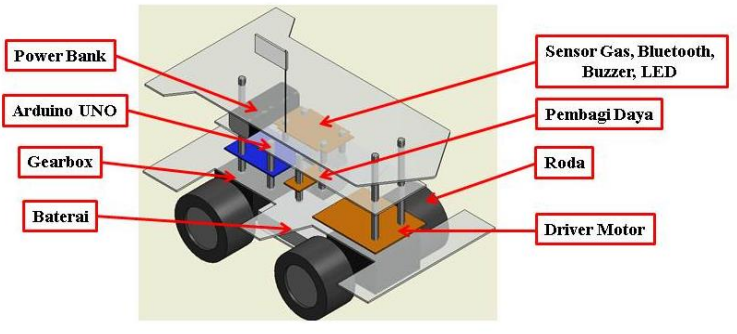

Gambar 8. Gambar rancangan robot pendeteksi gas metana

\subsection{Pembuatan Prototype Robot Pendeteksi Gas Metana}

Setelah tahap perancangan robot selesai dilakukan, maka robot dibuat berdasarkan pemilihan komponen yang sesuai dengan perancangan dan dana yang dimiliki.

\subsection{Pemrograman Robot}

Setelah bagian mekanik dan elektronik sudah selesai dibuat, robot akan diprogram. Untuk memprogramnya, arduino harus disambungkan ke laptop melalui kabel USB. Pengkoneksian arduino ke laptop dapat dilihat pada Gambar 9. 


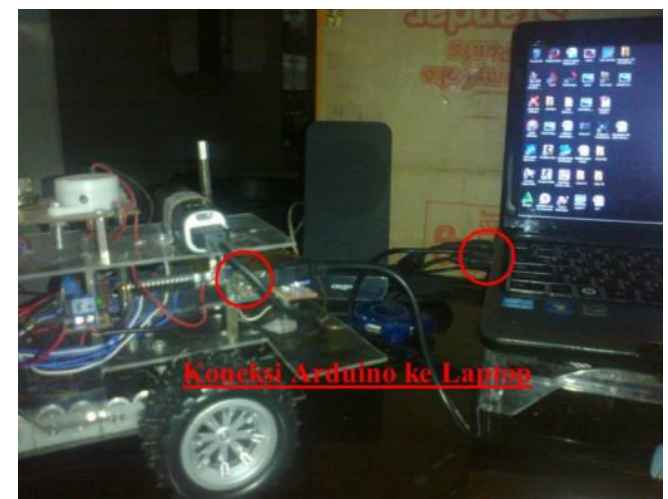

Gambar 9. Pengkoneksian arduino ke laptop

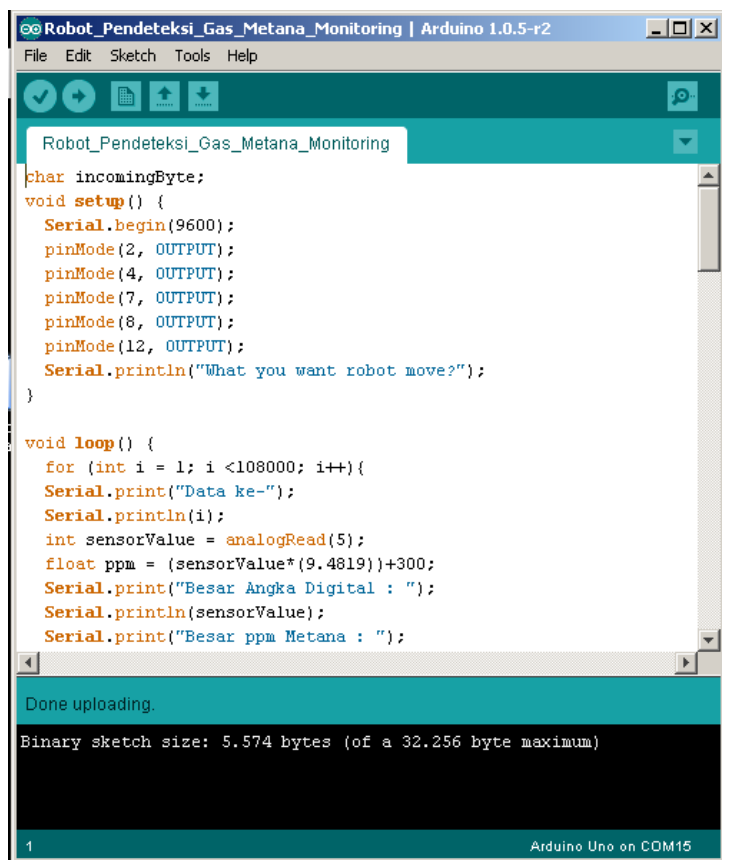

Gambar 10. Software Arduino IDE

Pemrograman robot dilakukan dengan software Arduino IDE. Dalam hal ini, terdapat dua jenis program yang dibuat yaitu program kalibrasi sensor dan program untuk mengetahui kadar ppm metana yang terbaca oleh sensor. Pada Gambar 10 diperlihatkan tampilan dari program Arduino IDE.

\section{HASIL DAN PEMBAHASAN}

\subsection{Hasil Rancangan Robot Pendeteksi Gas Metana}

Pembuatan alat dilakukan setelah perancangan dan proses produksi telah dikerjakan. Bentuk alat yang telah dibuat secara keseluruhan dapat dilihat pada Gambar 11.

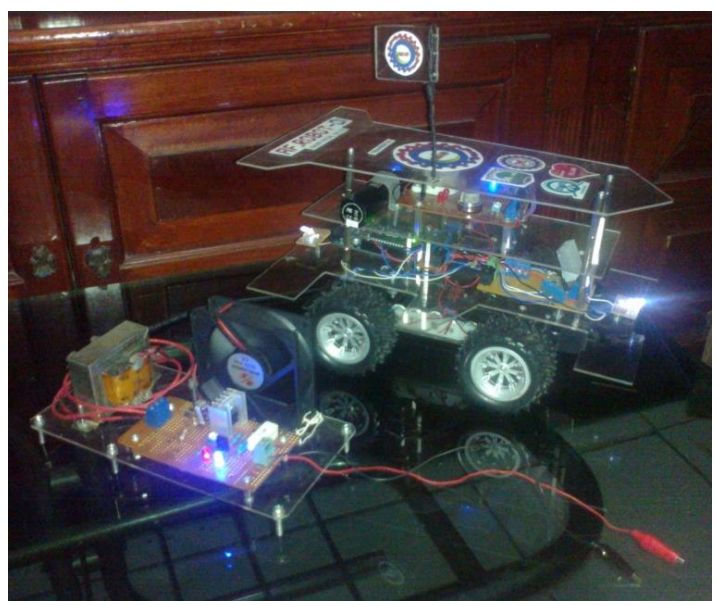

Gambar 11. Hasil rancangan robot pendeteksi gas metana dan charger-nya

\subsection{Hasil Pengujian Robot Pendeteksi Gas Metana}

Untuk melihat kemampuan robot, dilakukan berbagai macam pengujian. Pengujian yang dilakukan adalah sebagai berikut:

\subsubsection{Pengujian Pendeteksian Gas}

Salah satu sumber gas metana yang dengan mudah diperoleh adalah asap rokok. Berdasarkan hal ini, pengujian keberadaan gas metana dilakukan menggunakan sumber yang berasal dari asap rokok. Pengujian robot dilakukan didalam rumah dengan menggunakan 1 batang rokok yang sudah dibakar. Pengujian ini dilakukan menggunakan program mode Monitoring. Setelah robot mendeteksi adanya asap rokok, maka hasil kadar gas yang diperoleh dapat dimonitor. Hasil pengujian kadar gas metana dapat ditampilkan pada HP Android maupun pada komputer/ laptop seperti diperlihatkan pada Gambar 12.

Pada Tabel 1 diperlihatkan data hasil pengukuran kadar gas metana oleh robot. Dari Tabel 1, dapat dilihat bahwa semakin pekat asap rokok yang diberikan, angka digital yang terbaca oleh Arduino pun semakin membesar. Sewaktu terdapat gas metana, buzzer dan led berhasil aktif. 

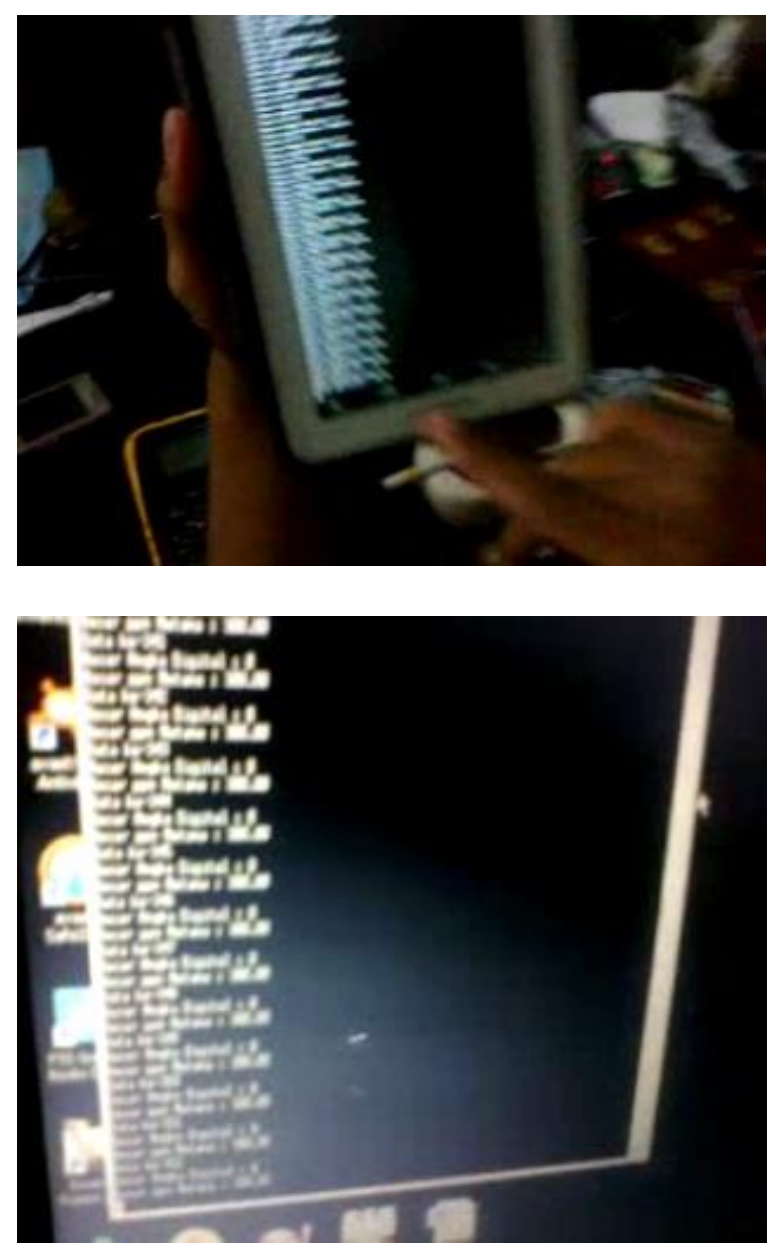

Gambar 12. Monitoring kadar gas metana dengan HP Android dan Laptop

Tabel 1. Data hasil pengujian gas metana

\begin{tabular}{lcccl}
\hline No & Menit ke- & Data ke- & $\begin{array}{c}\text { Angka } \\
\text { Digital }\end{array}$ & Kadar ppm \\
\hline 1 & 367 & 0 & 300 \\
2 & & 368 & 9 & 385,34 \\
3 & 6 & 369 & 10 & 394,82 \\
4 & & 370 & 7 & 366,37 \\
5 & & 371 & 5 & 347,41 \\
\hline 6 & & 576 & 0 & 300 \\
7 & 577 & 3 & 328,45 \\
8 & 9 & 578 & 4 & 337,93 \\
9 & & 579 & 4 & 337,93 \\
10 & & 580 & 2 & 318,96 \\
\hline 11 & & 655 & 0 & 300 \\
12 & & 656 & 4 & 337,93 \\
13 & 10 & 657 & 5 & 347,41 \\
14 & & 658 & 6 & 356,89 \\
15 & & 659 & 7 & 366,37 \\
\hline
\end{tabular}
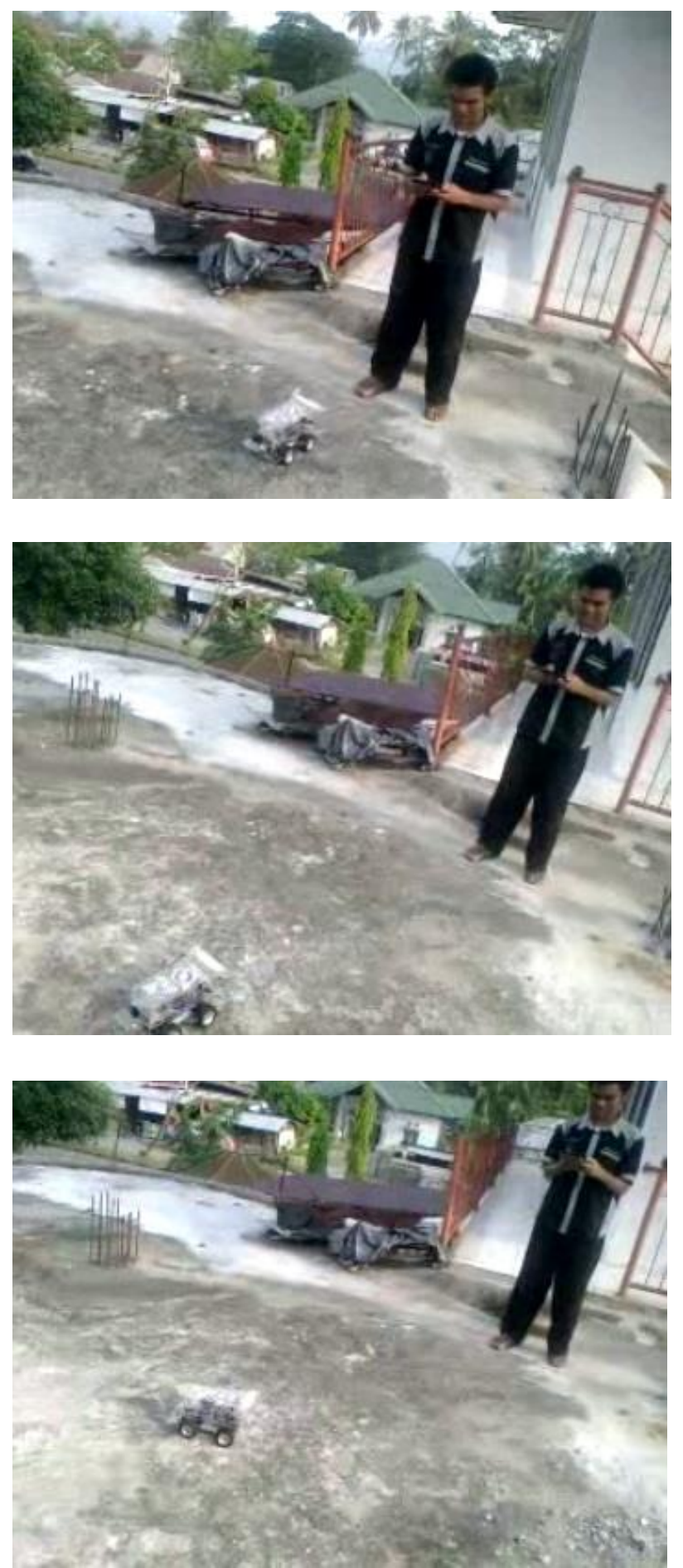

Gambar 13. Pengujian pergerakan maju dan berbelok pada jalan beton

\subsubsection{Pengujian Pergerakan Robot}

Pengujian pergerakan robot dilakukan pada jalan beton seperti terlihat pada Gambar 13. Setelah diuji, pergerakan maju dan mundur robot pada jalan berbeton cukup lancar. Untuk pergerakan berbelok, robot berhasil berbelok tetapi pergerakannya lebih berat dibandingkan gerak robot dalam arah maju- 

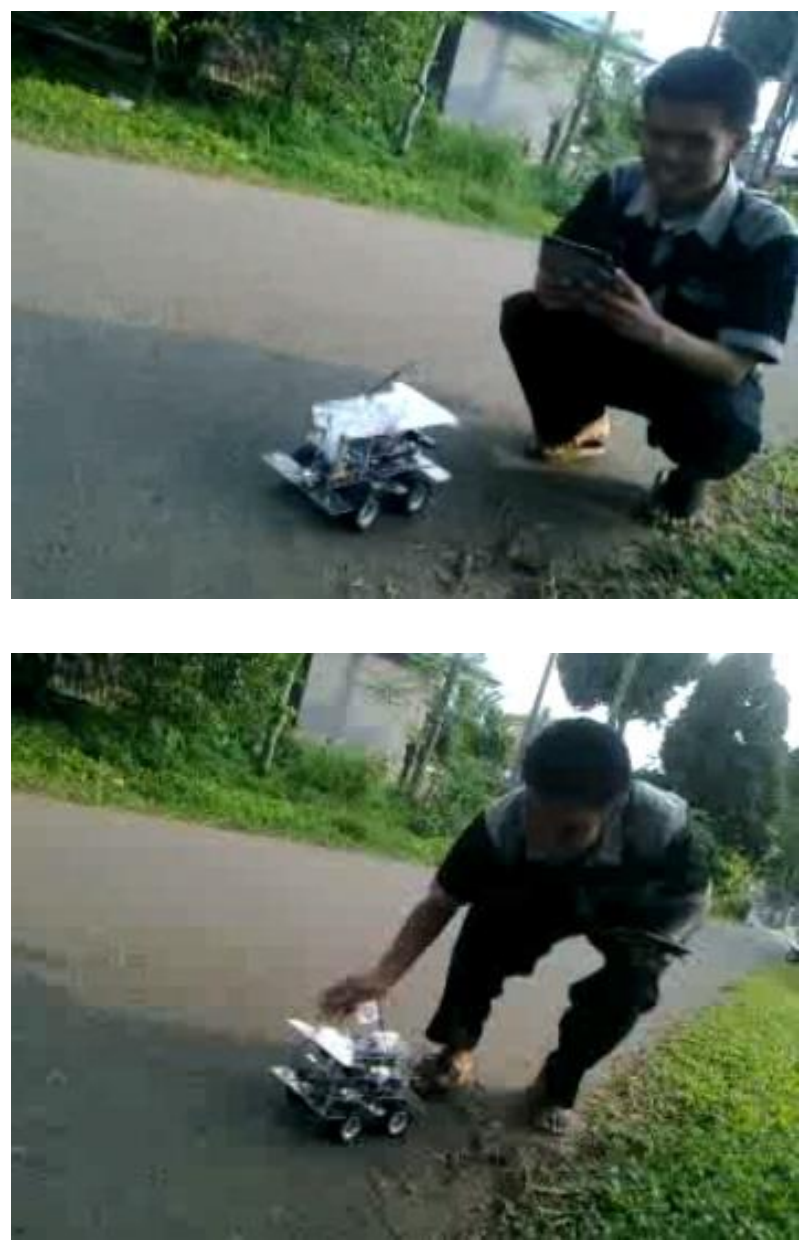

Gambar 13. Pengujian pergerakan maju dan berbelok pada jalan beton

mundur. Hasil yang lebih baik untuk berbelok diperoleh saat robot dioperasikan gerak maju terlebih dahulu baru berbelok.

Untuk pengujian gerak pada pendakian dilakukan pada lokasi kampus limau manis UNAND seperti yang terlihat pada Gambar 14. Hasil dari pengujian menunjukkan bahwa robot tidak bergerak dan hanya dapat bergerak sedikit. Hasil ini menunjukkan bahwa torsi yang dihasilkan oleh motor tidak mampu mengatasi beban gravitasi dan gesekan pada robot.

\section{KESIMPULAN DAN SARAN}

\subsection{Kesimpulan}

Dari hasil yang diperoleh dapat ditarik beberapa kesimpulan yaitu: (1) Berhasilnya dibuat prototype robot pendeteksi gas metana, namun masih belum dapat digunakan pada lingkungan tambang, karena daya baterai dan torsi yang ternyata belum cukup. Disamping itu, robot juga belum terkalibrasi dengan alat ukur standar untuk gas metana; (2) Dihasilkannya robot untuk model pengembangan ilmu robotika di Jurusan Teknik Mesin UNAND; dan (3) Dapat dikembangkan berbagai varian pengontrolan menggunakan mikrokontroler Arduino yang masih minim di lingkungan Teknik Mesin UNAND.

\section{2. $\quad$ Saran}

Untuk lebih baiknya robot pendeteksi gas metana ini, saran yang diberikan adalah sebagai berikut: (1) Untuk mendapatkan manufer yang lebih baik kapasitas arus baterai yang disarankan mencapai $4000 \mathrm{mAh}$ dan dimodifikasi komposisi motor dan roda gigi gearbox sehingga dihasilkan torsi yang lebih besar; dan (2) Untuk pengujian gas, diperlukan tempat pengujian khusus pada sumber gas metana.

\section{DAFTAR PUSTAKA}

[1] Analisa Ledakan Tambang Batubara di Sawahlunto.

http://cendikiamerangin.blogspot.com/2010/11 lanalisa-ledakan-tambang-batubara-di.html (diakses pada 03 November 2013)

[2] Methane.

https://en.wikipedia.org/wiki/Methane (diakses pada 03 November 2013)

[3] A. Nalwan. Teknik Rancang Bangun Robot. Yogyakarta: Penerbit Andi, 2012.

[4] W. Budihartono. Robotika Teori + Implementasi. Yogyakarta: Andi, 2010. 